\title{
Identification of Bronchodilator Responsiveness by Forced Oscillation Admittance in Children
}

\author{
YEN THI NGUYEN, BRUNO DEMOULIN, CYRIL SCHWEITZER, CLAUDE BONABEL-CHONE, AND FRANÇOIS MARCHAL \\ Service d'Explorations Fonctionnelles Pédiatriques [Y.T.N., C.S., C.B.-C., F.M.], Hôpital d'Enfants, Centre Hospitalier Universitaire de \\ Nancy, F-54511 Vandoeuvre les Nancy, France; Laboratoire de Physiologie [B.D., F.M.], Faculté de Médecine, University de Nancy, \\ F-54505, Vandoeuvre les Nancy, France
}

\begin{abstract}
The upper airway wall motion may be responsible for significant error when measuring respiratory resistance (Rrs) with the forced oscillation technique (FOT), particularly in young children with airway obstruction. Assessing the response to methacholine from the change in respiratory admittance (Ars, the reciprocal of respiratory impedance, Zrs) avoids the artifact. The aim of the study was to explore the possibility of assessing the response to a bronchodilator from the change in Ars. FOT measurements were performed at $12 \mathrm{~Hz}$ in 36 young children before and after salbutamol. Transrespiratory pressure was varied in two ways: directly at the mouth (standard generator, SG) and around the head (head generator, HG), a variant nearly free of upper airway artifact. Salbutamol induced significantly lower Rrs and Zrs change with SG than HG (respectively, $p=0.0003$ and 0.05 ). The relative change in Ars was not significantly different with SG and HG. Both estimates were significantly correlated $(p<0.0001)$. The change in Ars may thus be useful to avoid the upper airway artefact when assessing the response to salbutamol using the FOT in young children. (Pediatr Res 62: 348-352, 2007)
\end{abstract}

$\mathrm{A}^{n}$ n important step in assessing childhood asthma is to evaluate the effects of bronchodilator inhalation on the airways. The FOT is increasingly used in children because it is noninvasive, requires little cooperation, and is performed during spontaneous breathing (1). It may be more easily performed than forced spirometry in some young patients, as no voluntary respiratory manoeuvre is necessary. The child only needs to breathe quietly through a mouthpiece connected to the FOT apparatus. A small pressure variation is applied at the airway opening, usually directly at the mouth where flow is measured (standard generator, SG). The mechanical $\mathrm{Zrs}$ is calculated as the pressure flow ratio. A significant drawback of $\mathrm{SG}$ is that some flow is diverted with cheek vibration (Fig. 1, top). The so called upper airway artifact is particularly significant when the Zuaw is small relative to Zrs $(2,3)$, i.e. in the presence of airway obstruction (2) as well as in young children $(4,5)$. A significant underestimation of Zrs measured by SG $\left(\mathrm{Zrs}_{\mathrm{SG}}\right)$ may result. Holding the cheeks may be insufficient to prevent this artifact (6). Alternatively, if pressure is varied around the subject's head (head generator technique, HG, Fig.

Received September 28, 2006; accepted April 11, 2007.

Correspondence: François Marchal, M.D., Laboratoire de Physiologie, Faculté de Médecine, Avenue de la Forêt de Haye, F- 54505 Vandoeuvre les Nancy, France; e-mail: f.marchal@chu-nancy.fr

Supported by grant EA 3450 from ministry of research, France.
1 , bottom), the transmural pressure across the cheeks is minimal, most of the upper airway wall motion is prevented and Zrs measured with $\mathrm{HG}\left(\mathrm{Zrs}_{\mathrm{HG}}\right)$ is almost devoid of upper airway artefact $(5,7)$. The technique has been applied to various settings, including the pediatric lung function laboratory $(8,9)$. However, the HG set-up is cumbersome, available to a few laboratories and the configuration of the generator may decrease tolerance in younger children. Alternative ways to assess change in bronchomotor tone using FOT measurements would thus be particularly useful at this age.

Farré et al. (10) have proposed a simple method to effectively circumvent the upper airway artifact when estimating the overall respiratory response to methacholine. The airway effect of the bronchomotor agent is computed as change in Ars, the reciprocal of Zrs, as explained below. We are not aware of any data on this method applied to estimating reversibility induced by a bronchodilator. The issue is of particular importance because these effects need to be estimated routinely in asthmatic children.

The aim of the present study was therefore to test whether the airway response to salbutamol may be assessed using the change in Ars in young children. If the hypothesis is correct, then SG should yield similar estimate of the bronchodilatory effect of salbutamol than $\mathrm{HG}$, which is virtually free of upper airway artifact.

\section{MATERIALS AND METHODS}

Rationale. The rationale for analyzing FOT data as change in Ars during methacholine challenge has been presented in details elsewhere (10). Briefly, owing to the parallel arrangement of the respiratory impedance devoid of upper airway artifact (Zrs*) and Zuaw, $\mathrm{Zrs}_{\mathrm{SG}}$ is expressed as:

$$
1 / \mathrm{Zrs}_{\mathrm{SG}}=1 / \mathrm{Zrs}^{*}+1 / \mathrm{Zuaw}
$$

Using corresponding respiratory admittance $\left(\mathrm{Ars}_{\mathrm{SG}}\right.$ and $\left.\mathrm{Ars} *\right)$ and upper airway wall admittance (Auaw), eq. 1 may be written:

$$
\operatorname{Ars}_{\mathrm{SG}}=\text { Ars* }^{*}+\text { Auaw }
$$

Applying to describe baseline (subscript 1) and bronchodilation (subscript 2):

$$
\begin{aligned}
& \operatorname{Ars}_{\mathrm{SG} 1}=\operatorname{Ars}_{1}^{*}+\text { Auaw }_{1} \\
& \operatorname{Ars}_{\mathrm{SG} 2}=\operatorname{Ars}_{2}^{*}+\text { Auaw }_{2}
\end{aligned}
$$

\footnotetext{
Abbreviations: Ars, respiratory admittance; Auaw, upper airway admittance; FOT, forced oscillation technique; HG, head generator; Rrs, respiratory resistance; SG, standard generator; Xrs, respiratory reactance; Zrs, respiratory impedance; Zuaw, upper airway wall impedance
} 
Standard Generator

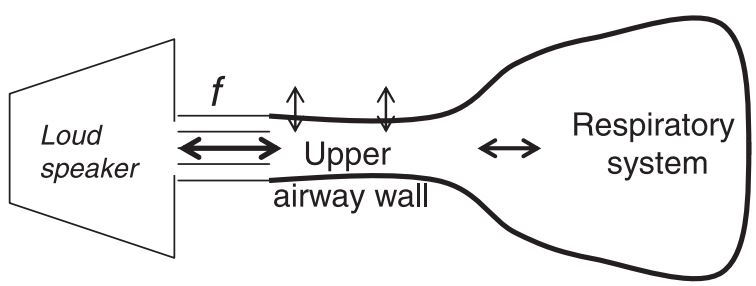

Head Generator

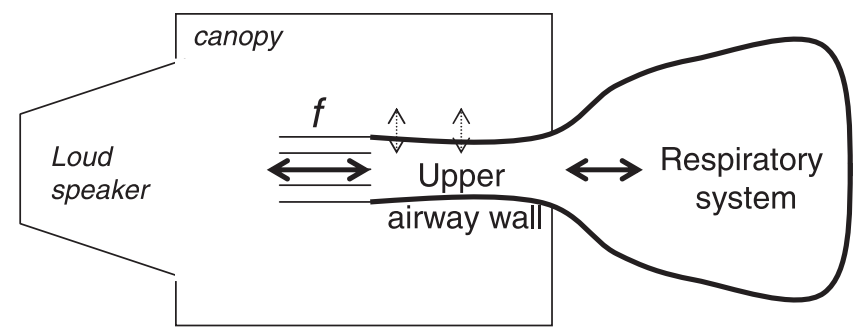

Figure 1. Simplified diagram of two variants of the forced oscillation technique. An oscillatory flow (arrow on left) is delivered by a pressure generator (loud speaker) through a flowmeter $(f)$ to the child's respiratory system (arrow on right). (Top) With standard generator, pressure varied only at the airway opening induces flow in upper airway wall (vertical arrows), which does not reach the respiratory system. (Bottom) With head generator, pressure is applied around the child's head enclosed in a canopy, i.e. both inside and outside the upper airway wall. The pressure difference across the upper airway wall is thus cancelled, except for the small pressure drop due to $f$. Upper airway wall vibration (dotted vertical arrows) is minimized and most of the measured flow enters the respiratory system.

$\Delta \mathrm{Ars}_{\mathrm{SG}}$, the observed change, is given by:

$$
\Delta \operatorname{Ars}_{\mathrm{SG}}=\mathrm{Ars}_{2}^{*}-\mathrm{Ars}_{1}^{*}+\mathrm{Auaw}_{2}-\mathrm{Auaw}_{1}
$$

As only Ars* is expected to change significantly after bronchodilation, Auaw $_{2}=$ Auaw $_{1}$ and therefore:

$$
\Delta \operatorname{Ars}_{\mathrm{SG}}=\operatorname{Ars}_{2}^{*}-\operatorname{Ars}_{1}^{*}
$$

It should be pointed out that, while Zrs may be split into a resistive component (Rrs) and nonresistive component (reactance, Xrs), such is not the case of Ars. Then, Ars is less selective for airway resistance than Rrs, and $\Delta$ Ars reflects changes in both resistive and nonresistive properties (elasticity, inertia) of the respiratory system.

Subjects. The study includes 36 young children (19 boys) with a history of asthma, where lung function was evaluated at baseline and after salbutamol. Age ranged from 3.5 to 7.5 y $(5.5 \pm 1.1 \mathrm{y})$ and height from 98 to $135 \mathrm{~cm}$ $(113 \pm 9 \mathrm{~cm})$. Bronchodilator therapy was discontinued more than $12 \mathrm{~h}$ before the study. As justified later on, the data were selected when, after salbutamol, both HG and SG showed a decrease in respiratory resistance (Rrs) and an increase or no change in Xrs. The protocol was approved by the committee for human subject protection in biologic research (Centre Hospitalier Universitaire de Nancy, France), explained to the child and his/her parents and informed consent was obtained.

Measurements. Zrs measurements were performed using the Pulmosfor apparatus (SEFAM, Vandoeuvre, France) that is in conformity with the recommendations issued by a task force from the European Respiratory Society (1). The child wore a nose clip and breathed through a mouthpiece and bacterial filter connected to a Fleisch no. 1 pneumotachograph (Metabo,
Epalinges, Switzerland). Sinusoidal pressure variation (1 $\mathrm{hPa}$ peak to peak) was applied at $12 \mathrm{~Hz}$ in two different ways: 1) around the subject's head enclosed in a translucent Plexiglas canopy (7) and 2) by connecting the loud speaker directly to the pneumotachograph, with the cheeks unsupported. In this configuration, fresh air was continuously flushed through the circuit to prevent $\mathrm{CO}_{2}$ accumulation. Pressure and flow signals were low-pass filtered at $32 \mathrm{~Hz}$ using analog filters and digitized at a sampling rate of $96 \mathrm{~Hz}$. The breathing component in the signals was eliminated using a fourth-order Butterworth high-pass filter with a corner frequency of $6 \mathrm{~Hz}$. The Fourier coefficients of pressure and flow were computed, Rrs and Xrs calculated oscillation cycle per oscillation cycle according to Navajas et al. (11). A filtering procedure was included to detect spurious data associated with rapid flow transients, low signal-to-noise ratio or glottis closure (12). Airflow, tidal volume, Rrs, and Xrs were displayed immediately after each acquisition to allow visual inspection and selection of the data, which were stored on disk. The data were reported in inspiration only so as to minimize variability resulting from change in glottis aperture (13) or flow limitation (14) during expiration.

The child was familiarized with the equipment, instructed to breathe calmly and regularly during trial measurements. Acquisitions lasting $30-45 \mathrm{~s}$ were then started using $\mathrm{HG}$ or SG and repeated immediately thereafter using SG or HG. The duration of the measurement allowed analyzing an average of $15-20$ breaths.

Two puffs of salbutamol (200 $\mu \mathrm{g}$, GlaxoSmithKline, Marly Le Roi, France) were delivered during tidal breathing through an inhalation chamber (Nespacer, Astra France, Monts, France) and the measurements were repeated as above $10 \mathrm{~min}$ thereafter.

Data analysis. Absolute and relative change after salbutamol from baseline were computed on $\operatorname{Rrs}\left(\Delta \mathrm{Rrs}_{\mathrm{SG}}, \Delta \% \mathrm{Rrs}_{\mathrm{SG}}, \Delta \mathrm{Rrs}_{\mathrm{HG}}, \Delta \% \mathrm{Rrs}_{\mathrm{HG}}\right)$ and $\mathrm{Zrs}$ $\left(\Delta \mathrm{Zrs}_{\mathrm{SG}}, \Delta \% \mathrm{Zrs}_{\mathrm{sG}}, \Delta \mathrm{Zrs}_{\mathrm{HG}}, \Delta \% \mathrm{Zrs}_{\mathrm{HG}}\right)$. The effect of salbutamol on Xrs was analyzed as absolute difference $\left(\Delta \mathrm{Xrs}_{\mathrm{SG}}, \Delta \mathrm{Xrs}_{\mathrm{HG}}\right)$ and, since the value was frequently close to zero, as percentage of baseline Zrs modulus $\left(\Delta \% \mathrm{Xrs}_{\mathrm{SG}}\right.$, $\left.\Delta \% \mathrm{Xrs}_{\mathrm{HG}}\right)$. The modulus of differences between salbutamol and baseline admittances was calculated $\left(\left|\Delta \operatorname{Ars}_{\mathrm{SG}}\right|,\left|\Delta \operatorname{Ars}_{\mathrm{HG}}\right|\right)$ and also expressed as $\%$ of the corresponding Ars modulus at baseline $\left(\left|\Delta \operatorname{Ars}_{\mathrm{SG}}\right| \%,\left|\Delta \mathrm{Ars}_{\mathrm{HG}}\right| \%\right)$. Statistical analysis was performed using ANOVA for repeated measurements and linear regression. Data are expressed as mean $+\mathrm{SD}$; a $p$ value $<0.05$ was retained as significant.

\section{RESULTS}

Impedance. Zrs data obtained with $\mathrm{HG}$ and $\mathrm{SG}$ before and after salbutamol are reported in Table 1. It may be seen that $\mathrm{Rrs}_{\mathrm{SG}}$ and $\mathrm{Zrs}_{\mathrm{SG}}$ are significantly lower than, respectively, $\operatorname{Rrs}_{\mathrm{HG}}$ or $\mathrm{Zrs}_{\mathrm{HG}}(p<0.0001)$ and $\Delta \mathrm{Rrs}_{\mathrm{SG}}$ and $\Delta \mathrm{Zrs}_{\mathrm{SG}}$ significantly smaller than, respectively, $\Delta \mathrm{Rrs}_{\mathrm{HG}}$ or $\Delta \mathrm{Zrs}_{\mathrm{HG}}(p=$ 0.0001). Relative changes described in Figure 2 also show significant underestimation of $\Delta \% \mathrm{Rrs}_{\mathrm{SG}}$ compared with $\Delta \% \operatorname{Rrs}_{\mathrm{HG}}(p=0.0003)$ as well as $\Delta \% \mathrm{Zrs}_{\mathrm{SG}}$ compared with $\Delta \% \mathrm{Zrs}_{\mathrm{HG}}(p=0.05)$. On the other hand, $\mathrm{Xrs}_{\mathrm{SG}}$ is significantly more negative than $\mathrm{Xrs}_{\mathrm{HG}}(p<0.0001)$ and $\Delta \mathrm{Xrs}_{\mathrm{SG}}$ significantly larger than $\Delta \mathrm{Xrs}_{\mathrm{HG}}(p<0.0001$, Table 1$)$. Accordingly, the change in Xrs as a fraction of the total respiratory impedance is expectedly larger for SG $(16.5 \pm 10.7 \%)$ than HG $(2.4 \pm 4.6 \%, p<0.0001)$.

Admittance. The Bland and Altman plot shows no increase in the scatter of individual differences $\mid \Delta$ Ars $_{\mathrm{SG}}|-| \Delta$ Ars $_{\mathrm{HG}} \mid$ when the corresponding mean increases ( $p=0.25$, Fig. 3$)$ and the mean difference in $\mid \Delta$ Ars $\mid$ is $0.009 \mathrm{~L} . \mathrm{s}^{-1} \cdot \mathrm{hPa}^{-1}\left|\Delta \mathrm{Ars}_{\mathrm{SG}}\right|$ and

\begin{tabular}{|c|c|c|c|c|c|c|}
\hline & $\operatorname{Rrs}_{\mathrm{HG}}$ & $\operatorname{Rrs}_{\mathrm{SG}}$ & $\mathrm{Xrs}_{\mathrm{HG}}$ & $\mathrm{Xrs}_{\mathrm{SG}}$ & $\mathrm{Zrs}_{\mathrm{HG}}$ & $\mathrm{Zrs}_{\mathrm{SG}}$ \\
\hline Baseline & $10.4 \pm 3.8$ & $7.1 \pm 1.5^{\circ}$ & $1.4 \pm 0.7$ & $-2.5 \pm 1.3^{\circ}$ & $10.5 \pm 3.7$ & $7.8 \pm 2.1^{\circ}$ \\
\hline Salbutamol & $7.6 \pm 2.1$ & $5.8 \pm 1.1^{\circ}$ & $1.7 \pm 0.6$ & $-1.2 \pm 0.7^{\circ}$ & $7.5 \pm 1.7$ & $5.9 \pm 1.2^{\circ}$ \\
\hline$\Delta$ & $-2.8 \pm 2.3$ & $-1.3 \pm 0.9^{*}$ & $0.3 \pm 0.5$ & $1.3 \pm 1.0^{\circ}$ & $-2.7 \pm 2.3$ & $-1.6 \pm 1.1^{+}$ \\
\hline
\end{tabular}

Table 1. Respiratory impedance (hPa.L $\left.L^{-1} . s\right)$ of the study population $(n=36)$

$\Delta$, Difference between salbutamol and baseline.

${ }^{\circ} p<0.0001,{ }^{*} p=0.0001,{ }^{+} p=0.001 v s$ corresponding $\mathrm{HG}$ value. 


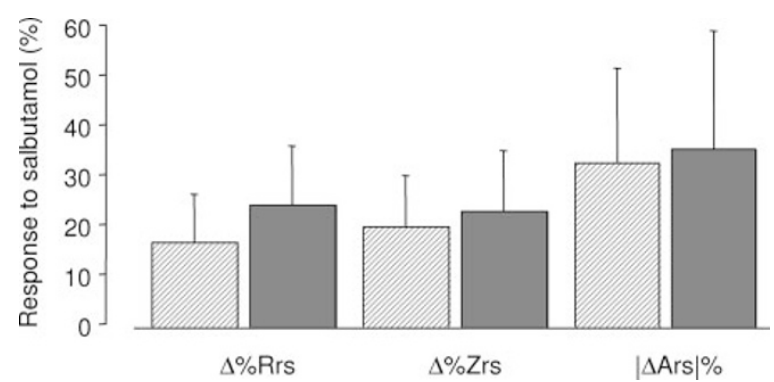

Figure 2. The response to salbutamol is expressed as percent decrease in respiratory resistance and impedance from baseline (respectively, $\Delta \%$ Rrs, $\Delta \% \mathrm{Zrs}$ ) and modulus of increase in respiratory admittance as percentage from baseline $(|\Delta \mathrm{Ars}| \%)$. Light columns: standard generator (SG); dark columns: head generator (HG). Note $\Delta \%$ Rrs and $\Delta \% \mathrm{Zrs}$ are significantly lower with SG than HG (respectively, $p=0.0003$ and 0.05 ) but $|\Delta \operatorname{Ars}| \%$ is equivalent with both techniques.

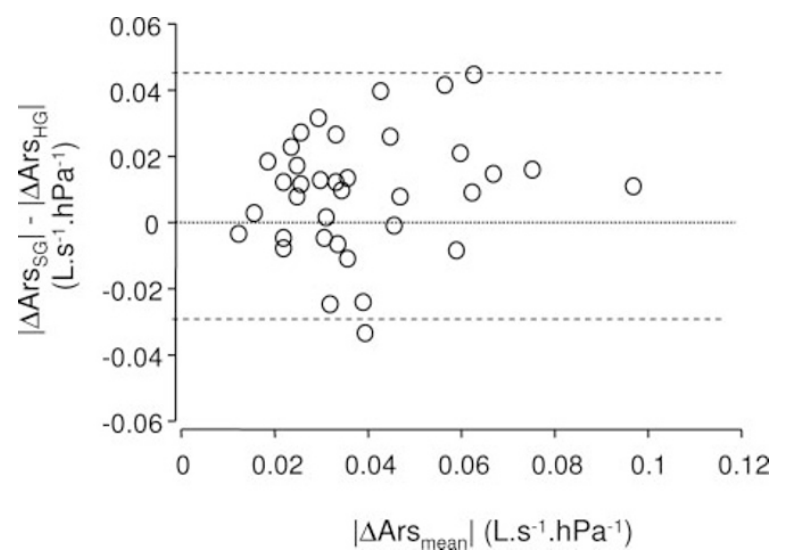

Figure 3. Bland and Altman plot shows no significant correlation between the difference $\left|\Delta \operatorname{Ars}_{\mathrm{SG}}\right|-\left|\Delta \operatorname{Ars}_{\mathrm{HG}}\right|$ and the corresponding mean $\left(\left|\Delta \operatorname{Ars}_{\text {mean }}\right|\right)$. Abbreviations as in Figure 2. Dotted lines indicate limits of agreement $(+$ and $-2 \mathrm{SD})$.

$\mid \Delta$ Ars $_{\mathrm{HG}} \mid$ are significantly correlated $\left(r^{2}=0.39, p<0.0001\right.$, Fig. $4 A$ ). However, as suggested by Figure 3, $\mid \Delta$ Ars $_{\mathrm{SG}} \mid$

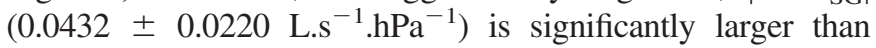
$\left|\Delta \operatorname{Ars}_{\mathrm{HG}}\right|\left(0.0337 \pm 0.0188 \mathrm{~L} . \mathrm{s}^{-1} \cdot \mathrm{hPa}^{-1}, p<0.0001\right)$. On the other hand, $\left|\Delta \operatorname{Ars}_{\mathrm{SG}}\right| \%$ and $\left|\Delta \operatorname{Ars}_{\mathrm{HG}}\right| \%$ are not different from each other (Fig. 2) and are also significantly correlated $\left(r^{2}=\right.$ $0.47, p<0.0001$ Fig. $4 B$ ).

The ability of Rrs, Ars, and Zrs to detect positive responses to salbutamol is compared between SG and HG in Figure 5, using percentage changes ranging from $15 \%$ to $40 \%$. It may be seen that discrepancy between paired curves is most between
$\mathrm{Rrs}_{\mathrm{SG}}$ and $\mathrm{Rrs}_{\mathrm{HG}}$, least between $\mathrm{Ars}_{\mathrm{SG}}$ and $\mathrm{Ars}_{\mathrm{HG}}$ and intermediate between $\mathrm{Zrs}_{\mathrm{SG}}$ and $\mathrm{Zrs}_{\mathrm{HG}}$.

\section{DISCUSSION}

To the best of our knowledge, this is the first report on mechanical respiratory admittance change induced by salbutamol in children. The study indicates that SG and HG yield concordant estimates of $|\Delta \operatorname{Ars}|$ and $|\Delta \operatorname{Ars}| \%$ with similar values for $\left|\Delta \mathrm{Ars}_{\mathrm{SG}}\right| \%$ and $\left|\Delta \mathrm{Ars}_{\mathrm{HG}}\right| \%$, while $\left|\Delta \mathrm{Ars}_{\mathrm{SG}}\right|$ appears significantly larger than $\left|\Delta \operatorname{Ars}_{\mathrm{HG}}\right|$.

The expected Zrs response to salbutamol includes a decrease in Rrs and, frequently, an increase in Xrs. These changes have repeatedly been documented in both healthy $(15,16)$ and stable asthmatic children (15-17). It was decided to include only data exhibiting a decrease in Rrs associated or not to an increase in Xrs because $|\Delta \operatorname{Ars}|$, as modulus of a complex quantity, is sign less, thus does not indicate the direction of the change and may theoretically result from any combination of $\mathrm{Ars}_{1}$ and $\mathrm{Ars}_{2}$ (eq. 3-6). Therefore, an improvement in airway function would not be differentiated from a change of equivalent magnitude expressing a paradoxical effect of salbutamol. Although worsening of airway function by beta-adrenergic drugs is unlikely in the current clinical context and has been reported in occasional children with cystic fibrosis $(18,19)$, involving spirometry rather than $\mathrm{Zrs}$ (20), we felt it mandatory, at least from a theoretical point of view, to discard any ambiguous $|\Delta \operatorname{Ars}|$ data. The upper airway artifact is expected to attenuate the magnitude of change in Rrs induced by a bronchomotor intervention but unlikely to completely abolish-let alone reverse-this change. Therefore, whenever $\operatorname{Rrs}_{S G}$ is observed to decrease after salbutamol, the role of $\left|\Delta \mathrm{Ars}_{\mathrm{SG}}\right| \%$ would be to more accurately describe the amplitude of the response.

In the current study, the Bland and Altman plot (Fig. 3) indicates no systematic increase in the differences between SG and $\mathrm{HG}$ as the mean difference increases. The observed range for these limits of agreement (Fig. 3) and the scatter of data points in Figure 4 could be explained by the fact that Rrs and Xrs contributed differently to the measurement variability with HG and SG. In addition, the measurements were not carried out simultaneously and the effect of time was likely to add to the variability in these asthmatic children (21). The significant correlation between $\left|\Delta \mathrm{Ars}_{\mathrm{SG}}\right|$ and $\left|\Delta \mathrm{Ars}_{\mathrm{HG}}\right|$ described in Figure $4 A$ is similar to that previously reported with data on induced bronchomotor tone (10). However, in the latter study,
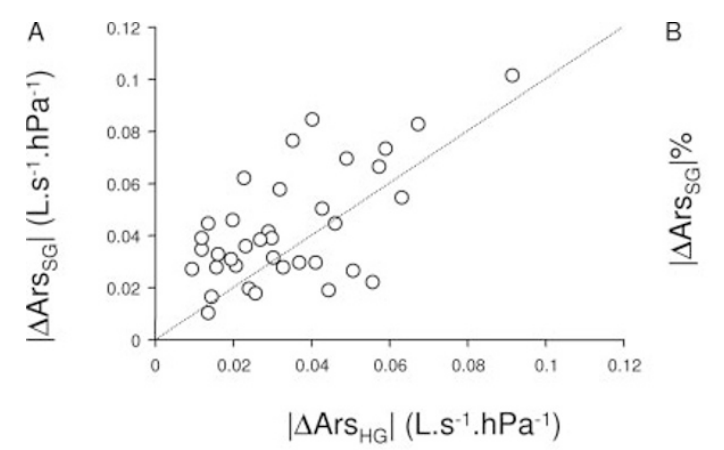

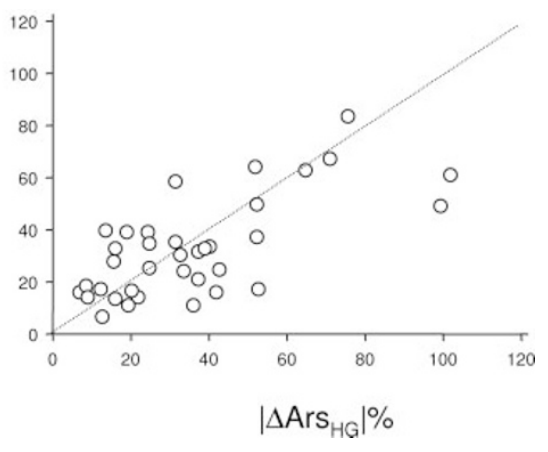

Figure 4. Significant correlation between (A) $\left|\Delta \mathrm{Ars}_{\mathrm{HG}}\right|$ and $\left|\Delta \mathrm{Ars}_{\mathrm{SG}}\right|$ in 36 subjects $\left(r^{2}=0.39, p<0.0001\right)$ and $(B)\left|\Delta \operatorname{Ars}_{\mathrm{HG}}\right| \%$ and $\left|\Delta \operatorname{Ars}_{\mathrm{SG}}\right| \%\left(r^{2}=0.47, p<0.0001\right)$. Identity lines are shown. 


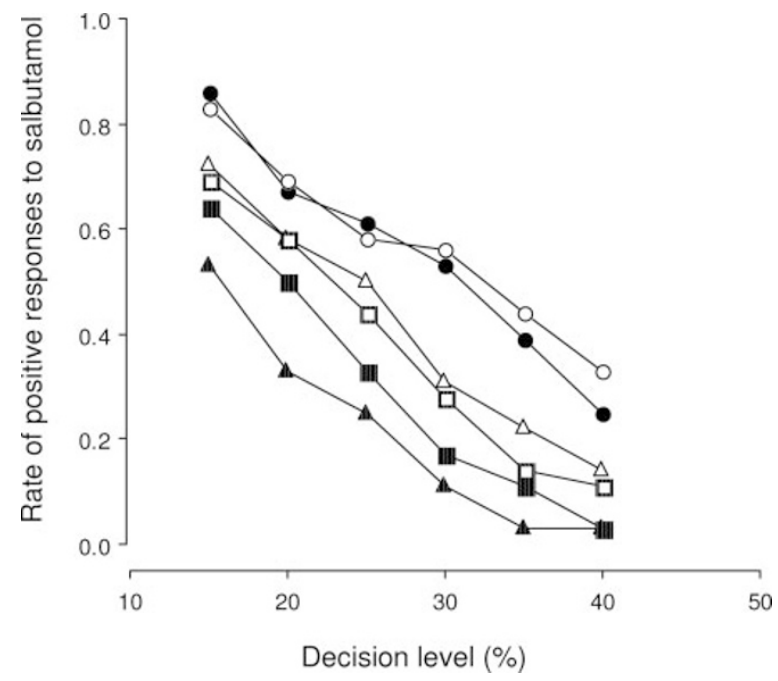

Figure 5. Rate of positive responses to salbutamol computed in 36 children at different decision levels for each parameter. Circle, Ars; square, Zrs; triangle, Rrs. Filled symbol, standard generator; open symbol, head generator. Note difference between SG and HG is largest with Rrs, smallest with Ars, intermediate with Zrs. Abbreviations as in Figure 2.

$\left|\Delta \operatorname{Ars}_{\mathrm{SG}}\right|$ was not statistically different from $\left|\Delta \mathrm{Ars}_{\mathrm{HG}}\right|$, e.g. $0.0295 \mathrm{~L} . \mathrm{s}^{-1} \cdot \mathrm{hPa}^{-1}$ and $0.0327 \mathrm{~L} . \mathrm{s}^{-1} \cdot \mathrm{hPa}^{-1}$, respectively, at $10 \mathrm{~Hz}$ (10), while we reported a mean difference between $\left|\Delta \operatorname{Ars}_{\mathrm{SG}}\right|$ and $\left|\Delta \mathrm{Ars}_{\mathrm{HG}}\right|$ of $0.009 \mathrm{~L} \cdot \mathrm{s}^{-1} \cdot \mathrm{hPa}^{-1}$. Methodological discrepancies exist between the two studies regarding the excitation signal (pseudo-random noise versus sine wave), the type of computation (fast Fourier transform versus oscillation per oscillation), the period of the respiratory cycle analyzed (whole breath versus inspiration). A different effect of salbutamol on inspiration and expiration resistance has been suggested in children (22) and this could explain the difference between the current results-analyzed in inspiration oscillation per oscillation - and those by Farré et al. (10) obtained on whole breaths by fast Fourier transform. Finally, some difference between $\left|\Delta \mathrm{Ars}_{\mathrm{HG}}\right|$ and $\left|\Delta \mathrm{Ars}_{\mathrm{SG}}\right|$ can be expected from the arrangement of Zuaw and the pneumotachograph. Indeed, with $\mathrm{HG}$, these impedances are in parallel and some of the respiratory flow, shunted by airway walls, is not seen by the pneumotachograph (7). However, based on the current pneumotachograph impedance and Zuaw values estimated in children (4), the effect is likely to be minimal.

Whatever the reason for the difference between $\left|\Delta \mathrm{Ars}_{\mathrm{HG}}\right|$ and $\left|\Delta \mathrm{Ars}_{\mathrm{SG}}\right|$, it is of interest that relative changes-which are the important quantities in practice-were significantly correlated (Fig. $4 B$ ) and not significantly different. $\left|\Delta \mathrm{Ars}_{\mathrm{SG}}\right| \%$ should thus be equivalent to $\left|\Delta \operatorname{Ars}_{\mathrm{HG}}\right| \%$ in evaluating the respiratory response to salbutamol. On the other hand, $\Delta \% \mathrm{Zrs}_{\mathrm{SG}}$ was found significantly smaller than $\Delta \% \mathrm{Zrs}_{\mathrm{HG}}$, although the difference was less significant than for $\Delta \%$ Rrs (Fig. 2). This expresses the fact that both reactive and resistive changes combine in $\Delta \% \mathrm{Zrs}$, with more change in Xrs being detected by SG compared with HG. It should be noted that, for comparison purpose, measurements were performed with cheeks unsupported, so as to have similar upper airway impedance with both HG and SG. Holding the cheeks with SG would be likely to further decrease the difference between $\Delta \% \mathrm{Zrs}_{\mathrm{HG}}$ and $\Delta \% \mathrm{Zrs}_{\mathrm{SG}}$.

$\left|\Delta \mathrm{Ars}_{\mathrm{SG}}\right| \%$ appears particularly helpful in routine since the FOT is mostly used in the SG mode in children and the computation may easily be performed on any set of Zrs data. The current protocol was not designed for sensitivity and specificity studies. To assess the potential diagnostic value of $\left|\Delta \mathrm{Ars}_{\mathrm{SG}}\right| \%$, the rate of positive responses to salbutamol was computed at different decision levels for each parameter. Figure 5 shows the difference between SG and HG is marked for Rrs, intermediate for Zrs, and minimal for Ars. Thus, correcting for upper airway artifact by $\Delta \%$ Ars is likely to improve the rate of identification of asthmatic children based on this estimate of their airway response to salbutamol. The improved value of $\left|\Delta \operatorname{Ars}_{S G}\right| \%$ in quantifying bronchodilation, compared with $\Delta \% \mathrm{Zrs}$ and $\Delta \% \mathrm{Rrs}$, remains to be established in sensitivity/specificity studies. We have limited the study to the excitation frequency routinely used in our laboratory. Twelve hertz has been selected empirically for a long time because of the common observation of corrupted data in young asthmatics at lower frequencies. It must be noted that, as it minimizes the upper airway wall motion, the HG has the significant advantage to allow the use of frequencies a few hertz higher than the range recommended for SG (1). It is of interest that when using a pseudorandom noise (multifrequency) excitation signal, the $|\Delta \operatorname{Ars}|$ response to methacholine in children was found to be independent of frequency with both SG and HG (10). Thus, a further potential advantage of $\mid \Delta$ Ars $_{\mathrm{SG}} \mid \%$ would be to improve the signal-to-noise ratio by allowing higher excitation frequencies to be used without majoring the upper airway artiact.

The FOT has the potential to allow detailed description of mechanical respiratory characteristics from amplitude and phase of the pressure-flow relationship. Both Rrs and Xrs may be altered by a bronchodilator agent and, with conventional model interpretation, Rrs characterizes the flow resistive respiratory properties and apparent elasticity is described by Xrs $(1,23,24)$. Such interpretation is of course not possible with $\mid \Delta$ Ars $\mid$, which is contributed to by both resistive and reactive components. $|\Delta \mathrm{Ars}|$ in general characterizes the overall ease to respiratory flow and, at the particular resonant frequency, is equivalent to the change in respiratory conductance. On the other hand, interpreting changes in $\mathrm{Rrs}_{\mathrm{SG}}$ and $\mathrm{Xrs}_{\mathrm{SG}}$ induced by salbutamol, respectively, as change in bronchial diameter and as improvement in apparent elasticity is only theoretical, because the cheek artifact, not accounted for in the conventional model, modulates both responses (25). Therefore, the inconvenience of losing the ability to dissociate respiratory resistive and reactive effects of bronchodilator inhalation appears to be balanced by the fact that, in contrast to $\Delta$ Rrs or $\Delta \mathrm{Zrs},\left|\Delta \mathrm{Ars}_{\mathrm{SG}}\right|$ is free of upper airway artifact. Here again, it should be stressed that conventional FOT parameters should be complemented with, rather than replaced by, $\left|\Delta \mathrm{Ars}_{\mathrm{SG}}\right|$ for a more accurate estimation of the bronchodilator effect.

Altogether, the current study indicates $\mid \Delta$ Ars $_{\mathrm{SG}} \mid \%$ may be a valuable tool when evaluating reversibility of airway obstruction by bronchodilator therapy in asthmatic children. A qualitative assessment of Rrs and Xrs is necessary to insure the 
direction of the change. Further studies are needed in routine setting to assess the sensitivity and specificity of $\left|\Delta \mathrm{Ars}_{\mathrm{SG}}\right| \%$ in detecting the response to bronchodilator in children with reference to conventional FOT parameters in a range of excitation frequencies.

Acknowledgments. The authors thank Prof. Ramon Farré for fruitful discussion and suggestions; Gérard Colin, Claude Duvivier, and Sylvie Méline for technical assistance; and Françoise Bebon and Elisabeth Gerhardt for secretarial help.

\section{REFERENCES}

1. Oostveen E, MacLeod D, Lorino H, Farre R, Hantos Z, Desager K, Marchal F 2003 The forced oscillation technique in clinical practice: methodology, recommendations and future developments. Eur Respir J 22:1026-1041

2. Peslin R, Duvivier C, Gallina C, Cervantes P 1985 Upper airway artifact in respiratory impedance measurements. Am Rev Respir Dis 132:712-714

3. Peslin R, Duvivier C, Jardin P 1984 Upper airway walls impedance measured with head plethysmograph. J Appl Physiol 57:596-600

4. Marchal F, Haouzi P, Peslin R, Duvivier C, Gallina C 1992 Mechanical properties of the upper airway wall in children and their influence on respiratory impedance measurements. Pediatr Pulmonol 13:28-33

5. Cauberghs M, Van de Woestijne KP 1989 Effect of upper airway shunt and series properties on respiratory impedance measurements. J Appl Physiol 66:2274-2279

6. Michaelson ED, Grassman ED, Peters WR 1975 Pulmonary mechanics by spectral analysis of forced random noise. J Clin Invest 56:1210-1230

7. Peslin R, Duvivier C, Didelon J, Gallina C 1985 Respiratory impedance measured with head generator to minimize upper airway shunt. J Appl Physiol 59:1790-1795

8. Marchal F, Loos N, Monin P, Peslin R 1999 Methacholine-induced volume dependence of respiratory resistance in preschool children. Eur Respir J 14:1167-1174

9. Mazurek H, Willim G, Marchal F, Haluszka J, Tomalak W 2000 Input respiratory impedance measured by head generator in preschool children. Pediatr Pulmonol 30:47-55

10. Farre R, Rotger M, Marchal F, Peslin R, Navajas D 1999 Assessment of bronchial reactivity by forced oscillation admittance avoids the upper airway artefact. Eur Respir J 13:761-766
11. Navajas D, Farre R, Rotger M, Peslin R 1988 A new estimator to minimize the error due to breathing in the measurement of respiratory impedance. IEEE Trans Biomed Eng 35:1001-1005

12. Marchal F, Schweitzer C, Demoulin B, Chone C, Peslin R 2004 Filtering artefacts in measurements of forced oscillation respiratory impedance in young children. Physiol Meas 25:1153-1166

13. Schweitzer C, Chone C, Marchal F 2003 Influence of data filtering on reliability of respiratory impedance and derived parameters in children. Pediatr Pulmonol 36:502_ 508

14. Dellaca RL, Santus P, Aliverti A, Stevenson N, Centanni S, Macklem PT, Pedotti A, Calverley PM 2004 Detection of expiratory flow limitation in COPD using the forced oscillation technique. Eur Respir J 23:232-240

15. Hellinckx J, De Boeck K, Bande-Knops J, van der Poel M, Demedts M 1998 Bronchodilator response in 3-6.5 years old healthy and stable asthmatic children. Eur Respir J 12:438-443

16. Nielsen KG, Bisgaard H 2001 Discriminative capacity of bronchodilator response measured with three different lung function techniques in asthmatic and healthy children aged 2 to 5 years. Am J Respir Crit Care Med 164:554-559

17. Mazurek HK, Marchal F, Derelle J, Hatahet R, Moneret-Vautrin D, Monin P 1995 Specificity and sensitivity of respiratory impedance in assessing reversibility of airway obstruction in children. Chest 107:996-1002

18. Landau LI, Phelan PD 1973 The variable effect of a bronchodilating agent on pulmonary function in cystic fibrosis. J Pediatr 82:863-868

19. Zach MS, Oberwaldner B, Forche G, Polgar G 1985 Bronchodilators increase airway instability in cystic fibrosis. Am Rev Respir Dis 131:537-543

20. Hellinckx J, De Boeck K, Demedts M 1998 No paradoxical bronchodilator response with forced oscillation technique in children with cystic fibrosis. Chest 113:55-59

21. Trubel H, Banikol WK 2005 Variability analysis of oscillatory airway resistance in children. Eur J Appl Physiol 94:364-370

22. Hadjikoumi I, Hassan A, Milner AD 2003 Effects of respiratory timing and cheek support on resistance measurements, before and after bronchodilation in asthmatic children using the interrupter technique. Pediatr Pulmonol 36:495-501

23. Peslin R, Fredberg J 1986 Oscillation mechanics of the respiratory system. In Fishman P, Macklem PT, Mead J (eds) Handbook of Physiology, section 3. Williams \& Wilkins, Baltimore, pp 145-177

24. Marchal F, Schweitzer C, Thuy LV 2005 Forced oscillations, interrupter technique and body plethysmography in the preschool child. Paediatr Respir Rev 6:278-284

25. Marchal F, Mazurek H, Habib M, Duvivier C, Derelle J, Peslin R 1994 Input respiratory impedance to estimate airway hyperreactivity in children: standard method versus head generator. Eur Respir J 7:601-607 